\title{
Wireless Communications for Airport Surface: An Evaluation of Requirements
}

\author{
Rafael D. Apaza \\ Federal Aviation Administration \\ 8808 Beck Road \\ Belleville, MI 48111 \\ 734-487-7327 \\ Rafael.Apaza@FAA.gov
}

\begin{abstract}
Reliable airport surface communications is vital in today's airport operations. Present Federal Aviation Administration (FAA), Airlines, and Airport Authority communications infrastructure is very diverse. Airports in the United States use either fiber optics, copper cable or leased telecommunications services to transport voice, data, and system monitoring information between FAA facilities and the Air Traffic Control Tower (ATCT). Copper cable is the most utilized in-airport communications medium by FAA. A large number of airports have an aging infrastructure that requires frequent maintenance and in some instances reliability is reduced due to performance limitations. A reduced number of FAA facilities use leased telecommunications services or fiber optic electronics to transport critical system information. Leased telecommunications services are costly and do not provide the diversity and redundancy required by large facilities.
\end{abstract}

FAA has an ongoing effort to refurbish its infrastructure. Significant funds are budgeted to repair or replace aging or damaged copper cable. Similarly, funds are allocated to deploy fiber optic systems. The continuous growth of airports coupled with modernization efforts have made buried copper/fiber cables vulnerable to cuts/digs. The impact a cable cut has on the National Airspace System (NAS) can range depending on the location of the cable cut, the type of cable impacted, the time of day the cable is cut, and the airport where the cable cut occurs. Most copper cables installed by FAA are point to point architectures. Consequently, facilities serviced by copper cables frequently lack the diversity and redundancy offered by fiber optic loops. Airline and Airport Authority have similar efforts in place designed to improve the efficiency of their operation by enhancing their communications infrastructure and services. ${ }^{12}$

To develop a surface wireless communications system, an understanding of existing and future voice and data communications requirements is necessary. This paper

\footnotetext{
${ }^{1}$ U.S. Government work not protected by U.S. copyright.

${ }^{2}$ IEEEAC paper \#1446, Version 1, Updated October 27, 2004
}

explores existing airport surface communications infrastructure, along with the data and voice communication requirements, within the U.S. A requirements evaluation for the Dallas Fort Worth Airport, one of the largest airports in the U.S., is presented.

\section{TABle of Contents}

1. INTRODUCTION

2. FEDERAL AVIATION REQUIREMENTS ................... 2

3. AIRLINE REQUIREMENTS .................................. 5

4. OTHER TENANT REQUIREMENTS......................... 5

5. DALlas Fort WORTH AIRPORT - REQUIREMENTS

EVALUATION.................................................................. 7

6. CONCLUSION........................................................9 9

REFERENCES.............................................................. 10

BIOGRAPHY ........................................................ 10

\section{INTRODUCTION}

The performance of the National Airspace System (NAS) is directly related to the performance of large airports through the US. Air Traffic Control (ATC), Airlines, Port Authority and other airport tenants are required to operate on precise schedules, reduced personnel, and shrinking budgets while maintaining a safe and efficient NAS operation. Consequently, reliable information distribution and sharing at an airport surface is paramount to an optimal NAS performance.

Airport surface communications at most airports today are divided primarily in two categories: air-ground and groundground. Tenants at different airports have different needs and may require different communication services. Given the diversity of services offered by the Federal Aviation Administration (FAA) at the terminal and surface domain's, ground-ground airport communications infrastructure is very diverse in its requirements. Most airports in the United States use fiber optics, copper cable, microwave systems or leased telco services to transport critical information between FAA field facilities and Air Traffic Control Tower (ATCT). Copper cable is the most utilized in-airport 
communications medium by the FAA, and numerous airports have an aging copper infrastructure averaging 15 years or greater. Consequently, the FAA has an ongoing effort to modernize its infrastructure by installing fiber optics at major airports, and new copper cable at smaller airports. A few airports use leased telco services or microwave systems to transport critical communications. These leased telco services are costly and diversity/redundancy requirements are difficult to achieve.

Air-ground voice communications for ATC operate in the 118 to $137 \mathrm{MHz}$ VHF band, and accommodate 720 channels using $25 \mathrm{KHz}$ channel bandwidth. This Amplitude Modulated system has been in operation for over 30 years and is reaching limitations due to spectrum allocation exhaustion [1]. Furthermore, the AM VHF system in use today is unable to transport digital information between ATC and the aircraft. Today's airport operations have increased requirements for information transfer and require more sophisticated communication systems to meet growing demands

Airline airport operations are required to operate with reduced error margins, with increasingly tight schedules and shrinking budgets. Access to status information on aircraft taxiing, gate information, operations updates, maintenance, de-icing and others is required to meet increasing travel demands and maintain a competitive edge. Today's airline air-ground communications rely on leased services and, depending on the size of operation, airline owned/leased wireless communication systems are used for internal airline communications.

The Port Authority is responsible for ensuring airport operations are efficient and able to meet the aviation requirements necessary for modern airports. Port Authority operations have communication requirements for monitoring airport grounds and, communicating with airport maintenance, airport security, the FAA and other tenants. Fire and Rescue at an airport has the responsibility to quickly respond to emergency situations on airport grounds.

It is envisioned that to support the growing demands for information transfer a hybrid communications system will be required. An ideal communications system would use existing communications assets and wireless technologies to increase reliability and availability. The continued use of a wired system would mitigate any potential frequency interference vulnerability a wireless system has and the use of a wireless system would mitigate the cable cut problems encountered at many airports today.

\section{Federal AViation ReQuirements}

A large airport operation requires reliable communication services to be in place to transport diverse navigation, surveillance, weather and voice communications information. These services usually require year-round availability with minimum or no service interruption. FAA airport communication requirements fit into two categories: operational and administrative. Operational circuits are services that must be available at all times. These circuits transport critical information vital to the operation of the NAS, and are required to provide 0.99999 service availability [2]. Administrative circuits, in contrast, do not require the same availability. These are used to coordinate equipment release for maintenance operations and any other airport activity in support of the NAS. Additionally, administrative circuits are used for communicating with remote electronic equipment to perform maintenance, monitoring or corrective tasks.

The following describes airport electronic systems requiring communication services, lists the type of communication services, and provides the number of circuits required per system. Communication service requirements vary depending on airport size. Table 1 list an approximation of circuits in use at a large airport and is not an exhaustive list of all circuits and services used.

Instrument Landing Systems (ILS) - An ILS system is designed to help aircraft land safely on a runway. A runway is normally equipped with Localizer (LOC), Glide Slope (GS) and Marker equipment and each has specific communication requirements. Depending on ILS equipment in use and runway category (Table 1), the number of circuit requirements can vary. An ILS system will require an average of 9-10 dedicated circuits, these are required to transport equipment status information to the ATCT and enable control of ILS electronics. When MARK-20 ILS systems are in use, transitioning to a wireless system becomes much easier.

Surveillance - Terminal radar assists air traffic controllers in guiding aircraft within their terminal airspace. Large airports usually have one or two terminal radar facilities on airport grounds. The radar facility houses two radar systems: a primary and a secondary (ATCBI/Mode S) system. The circuit connectivity requirement for a radar facility is between the radar facility and the ATCT. Considering an Airport Surveillance Radar (ASR-9) system at a large airport, 7 to 12 modems will be required to transport radar tracks, weather, MODE-S and radar system monitoring information. This will require the use of 7-12 dedicated communication circuits, usually provided by FAA cable, microwave, or leased dedicated communication services. 
Runway Visual Range (RVR) - The RVR system assists controllers in determining runway visibility conditions. RVR sensors are located at different points along a runway. Table 1 shows RVR circuit requirements. These services are dedicated and continuously available, usually requiring 3 circuits per runway.

Runway End Identification Lights (REIL) - REIL provides pilots with a rapid and positive identification of the approach end of the runway. REIL systems require one dedicated circuit.

\begin{tabular}{|c|c|c|c|c|c|}
\hline Facility Type & Service & Facility & No. of Circuits & Circuit Type & Throughput \\
\hline \multirow{6}{*}{$\begin{array}{c}\text { Instrument } \\
\text { Landing System } \\
\text { CAT-III }\end{array}$} & Localizer & LOC & 2 & 2 wire & $2400 \mathrm{Kbps}$ \\
\hline & Glide Slope & GS & 2 & 2 wire & $2400 \mathrm{Kbps}$ \\
\hline & Middle Marker & MM & 2 & 2 wire & $2400 \mathrm{Kbps}$ \\
\hline & Inner Marker & $\mathrm{IM}$ & 2 & 2 wire & $2400 \mathrm{Kbps}$ \\
\hline & Far Field Monitor & FFM & 2 & 2 wire & $2400 \mathrm{Kbps}$ \\
\hline & Administrative & Admin. & 2 & 2 wire & $\mathrm{N} / \mathrm{A}$ \\
\hline \multirow{4}{*}{ Radar System } & Primary Radar & ASR 9 & 5 & 4 wire & $9600 \mathrm{Kbps}$ \\
\hline & Primary Radar & $\begin{array}{c}\text { ASR 9 } \\
\text { Monitoring }\end{array}$ & 1 & 4 wire & $2400 \mathrm{Kbps}$ \\
\hline & Mode Select & Mode S & 1 & 4 wire & $9600 \mathrm{Kbps}$ \\
\hline & Administrative & Admin. & 1 & 2 wire & $\mathrm{N} / \mathrm{A}$ \\
\hline \multirow{3}{*}{$\begin{array}{c}\text { Runway Visual } \\
\text { Range }\end{array}$} & Rollout RVR & RO RVR & 1 & 2 wire & $\mathrm{N} / \mathrm{A}$ \\
\hline & Midpoint RVR & MID RVR & 1 & 2 wire & $\mathrm{N} / \mathrm{A}$ \\
\hline & Touchdown RVR & TD RVR & 1 & 2 wire & $\mathrm{N} / \mathrm{A}$ \\
\hline \multirow{4}{*}{ Visual Aids } & ALS Control & ALSF & 1 & 4 wire & $\mathrm{N} / \mathrm{A}$ \\
\hline & Monitoring Modem & ALSF & 1 & 4 wire & \\
\hline & \begin{tabular}{|l|} 
EG Start \\
\end{tabular} & ALSF & 1 & 4 wire & $\mathrm{N} / \mathrm{A}$ \\
\hline & Monitoring & REIL & 1 & 4 wire & $\mathrm{N} / \mathrm{A}$ \\
\hline \multirow{3}{*}{$\begin{array}{l}\text { Communications } \\
\text { Air- Ground }\end{array}$} & \multirow{3}{*}{$\begin{array}{l}\text { Remote } \\
\text { Transmitter } \\
\text { Receiver }\end{array}$} & RTR 1 & 8 & 4 wire & $\mathrm{N} / \mathrm{A}$ \\
\hline & & RTR 2 & 8 & 4 wire & $\mathrm{N} / \mathrm{A}$ \\
\hline & & RTR 3 & 4 & 4 wire & $\mathrm{N} / \mathrm{A}$ \\
\hline
\end{tabular}

Table 1. FAA Airport Surface Communication Services.

Airport Lighting System (ALS) - ALS equipment assists pilots in identifying runway direction under low visibility conditions and at night. It provides an extension of the runway centerline. Table 1 provides a listing of circuit requirements for an Airport Lighting System with Flashers (ALSF) ALSF-II system. These services are dedicated and continuously available, usually requiring 3 circuits per system.

Remote Transmitter/Receiver (RTR) - An RTR is used to provide communications between pilot and controllers. The number of frequencies and, sites, and the frequency arrangement determine the total number of circuits required. On average an RTR site has a total of six channels. Each channel has main and standby equipment for both transmitters and receivers, and requires a four-wire circuit between the RTR and ATCT.

A hypothetical airport having a Traffic Radar Approach Control (TRACON) and an ATCT would have the following requirements (see Table 2): An airport having two runways equipped with ILS CAT III systems at both runway ends, three RTR facilities with 20 frequency channels, RVR facilities for each runway, one ASR-9 Radar facility, four ALSF systems, and four Runway End Identifier Lights. The minimum circuit count to meet a tworunway airport will be 88 point-to-point connections. This would be the number of fixed circuits a wireless surface communications network would need to support in order to meet FAA in-airport communication requirements at this example airport. Most of these services are categorized as 
critical and need to have 0.99999 reliability and meet stringent security requirements.

\section{FAA Anticipated Future Requirements}

Other communication services under development need to be transported by either a wireless communications network or existing infrastructure. Flight Information Service (FIS) is a service that will provide near real-time flight information to the pilot. It is envisioned that graphical weather, Notice to Airmen (NOTAM) and other information will be available to the cockpit. Controller-Pilot Data Link Communications (CPDLC), a project that has been under test by FAA, is designed to reduce controller-pilot voice communications. Although testing has been primarily accomplished in the en-route flight domain, it is likely that future Data Link communications may be required on airport surface. Automatic Dependent Surveillance (ADS) provides aircraft location, identification, intent and other information to ATC and nearby aircraft. The wireless surface communications system could be used to provide surface transport services for ADS information. A wireless communications network is a potential candidate to deliver future voice and data communications directly to the aircraft.

\begin{tabular}{|c|c|c|c|c|c|}
\hline Facility Type & Service & Facility & No. of Circuits & Circuit Type & Throughput \\
\hline \multirow{6}{*}{$\begin{array}{c}\text { Instrument } \\
\text { Landing System } \\
\text { CAT-III }\end{array}$} & Localizer & LOC & 8 & 2 wire & $2400 \mathrm{Kbps}$ \\
\hline & Glide Slope & GS & 8 & 2 wire & $2400 \mathrm{Kbps}$ \\
\hline & Middle Marker & MM & 8 & 2 wire & $2400 \mathrm{Kbps}$ \\
\hline & Inner Marker & $\mathrm{IM}$ & 8 & 2 wire & $2400 \mathrm{Kbps}$ \\
\hline & Far Field Monitor & FFM & 4 & 2 wire & $2400 \mathrm{Kbps}$ \\
\hline & Administrative & Admin. & 2 & 2 wire & $\mathrm{N} / \mathrm{A}$ \\
\hline \multirow{4}{*}{ Radar System } & Primary Radar & ASR 9 & 5 & 4 wire & $9600 \mathrm{Kbps}$ \\
\hline & Primary Radar & $\begin{array}{c}\text { ASR } 9 \\
\text { Monitoring }\end{array}$ & 1 & 4 wire & $2400 \mathrm{Kbps}$ \\
\hline & Mode Select & Mode S & 1 & 4 wire & $9600 \mathrm{Kbps}$ \\
\hline & Administrative & Admin. & 1 & 2 wire & N/A \\
\hline \multirow{3}{*}{$\begin{array}{c}\text { Runway Visual } \\
\text { Range }\end{array}$} & Rollout RVR & RO RVR & 2 & 2 wire & $\mathrm{N} / \mathrm{A}$ \\
\hline & Midpoint RVR & MID RVR & 2 & 2 wire & $\mathrm{N} / \mathrm{A}$ \\
\hline & Touchdown RVR & TD RVR & 2 & 2 wire & $\mathrm{N} / \mathrm{A}$ \\
\hline \multirow{4}{*}{ Visual Aids } & ALS Control & ALSF & 4 & 4 wire & $\mathrm{N} / \mathrm{A}$ \\
\hline & Monitoring Modem & ALSF & 4 & 4 wire & \\
\hline & \begin{tabular}{|l|} 
EG Start \\
\end{tabular} & ALSF & 4 & 4 wire & N/A \\
\hline & Monitoring & REIL & 4 & 4 wire & $\mathrm{N} / \mathrm{A}$ \\
\hline \multirow{3}{*}{$\begin{array}{l}\text { Communications } \\
\text { Air- Ground }\end{array}$} & \multirow{3}{*}{$\begin{array}{l}\text { Remote } \\
\text { Transmitter } \\
\text { Receiver }\end{array}$} & RTR 1 & 8 & 4 wire & $\mathrm{N} / \mathrm{A}$ \\
\hline & & RTR 2 & 8 & 4 wire & $\mathrm{N} / \mathrm{A}$ \\
\hline & & RTR 3 & 4 & 4 wire & $\mathrm{N} / \mathrm{A}$ \\
\hline
\end{tabular}

Table 2. FAA Airport Surface Communication Example. 


\section{AIRLINE REQUIREMENTS}

Airline communication requirements vary depending on airport size, airline operation, and services provided. At a major hub, a large airline provides a variety of services including aircraft fleet maintenance, ramp management and control, airline tower control for aircraft ramp and gate management. These diverse operations require a combination of wired and wireless communications. Aircraft maintenance operations require wireless communications with the aircraft, other maintenance personnel, and external facilities. For maintenance operations, usually trunk radios are used for communications between maintenance crews, however, these radios operate outside the aeronautical spectrum. To communicate with an aircraft when in flight or taxiing, airline maintenance personnel use VHF voice communication frequencies specifically assigned for this use. These frequency assignments are leased from a third party and managed by the airline. They are frequently used to communicate with the aircraft crew and for various other purposes. Airline pilots can use this frequency to communicate problems to maintenance personnel, and to provide status of equipment performance. Furthermore, this frequency may be used to relate information to the airline crew when the data link malfunctions or fails. Data link communication is also available to airlines. Leased data link services are offered in the aeronautical VHF spectrum that enables data communications to and from the aircraft. ARINC Communications Addressing and Reporting System (ACARS) is a service that enables airlines to communicate digitally with its fleet. This service is provided for all flight domains including surface. ACARS is used to provide Digital ATIS and Pre-Departure Clearance services at surface and terminal operations.

VHF radios operating in the aeronautical spectrum are used for ground communications at the airline ramp tower. This communication is typically conducted between the aircraft crew and the personnel manning the airline tower. An example of its use is to communicate gate arrival information while the aircraft is taxiing to the terminal.

In service aircraft require diverse communications while at the gate, and in today's airports it is accomplished using diverse media. Route manuals that include navigation information, aircraft manuals, flight data recorder, and inflight entertainment information can be exchanged or updated while the aircraft is stopped at the gate. In general, this information is not time critical and a wireless surface network could be used to meet this and other similar requirements. Additionally, coordination between ground and aircraft can include fueling, crew management, aircraft catering, passenger list, preliminary load figures, rotation data, de-icing requests and others. All this information can be exchanged via wireless media whether the aircraft is in motion or stationary.

As indicated above, there are many opportunities for communications using wireless technology. Future improvements to airline communications for airport operations should include a wireless communications system that provides maintenance personnel access to aircraft information. Aircraft technicians, using a portable computer, should be able to connect to a local information server, upload aircraft technical information, and download parameter data directly from aircraft monitoring access ports. This would enable more efficient problem detection and reporting process. Another possible benefit of a wireless communication system is that it can be used by airport maintenance operations to upload aeronautical information directly to the aircraft without requiring the aircraft to be out of service. Weather and ATIS information, flight plan data, pre-departure clearance, out, off, on, in (OOOI) and flight log information are some of the many applications that could be transported using an airport surface wireless system.

Aircraft cargo operations can obtain similar benefits from wireless networks. Present cargo operations use the same communication services used by airlines to communicate with their aircraft fleet. Cargo operations also use a trunk radio system for ground communications between crew employees loading and unloading aircraft. Wireless communication systems are also employed to scan packages. These are usually low power, low mobility Wireless Local Area Networks. An airport wireless network will be able to enhance communication services between the aircraft crew and airport cargo flight operations.

\section{OTHER TENANT REQUIREMENTS}

An airport may have numerous tenants requiring communications; the following is not an exhaustive description of all possible airport tenants but a description of tenants directly involved in maintaining an airport or supporting an airline operation.

The Port Authority is in charge of managing the airport and ensuring airport grounds are in optimal operating condition. Today's airports require high security, minimal runway/taxiway down time, faster maintenance services and the ability to adjust to changing operating conditions. To ensure airports run effectively, efficiently and free of incidents, airport operations have a need for robust and reliable communications systems. Some of the functions an airport operator may perform include airport grounds 
maintenance, runway and taxiway lighting facilities maintenance, airport security, ingress and egress to airport grounds, monitoring airport operations areas, updating and modernization of airport infrastructure, snow removal, and ensuring a problem-free operation. To accomplish these functions, the Port Authority utilizes both wired and wireless communication systems. To manage the diverse operational requirements, most airports employ some form of wireless communication systems. Some of the principal wireless communication requirements include communications with ground maintenance crews, airport security, security checkpoints and more.

Maintenance on airport grounds performed by Port Authority operations is an ongoing activity. Repairing taxiways, runways and other airfield activities require staying in close contact with ATC. The communications for this type of activity usually require AT ground control frequencies, and trunk radio systems for communication with other maintenance personnel. At busy airport locations, ground control frequencies can be congested and contact with AT ground control may require prolonged waiting periods. Future communication systems should provide improved access to AT for coordinating surface movement. Also, wireless data link communications should enable airport maintenance personnel access to a wide variety of airport information along with the ability to coordinate and inform tenants of event status.

Airport security is responsible for monitoring and overseeing the safe and secure operation inside airport grounds. They are responsible for responding to any incidents or events reported inside the airfield fence, and escorting contractors or other personnel to locations inside airport property. Airport security has a need to maintain constant contact with other airport security personnel and central command operations. Currently, secure trunk radio systems are used to meet voice communications needs.

Fire and Rescue operations require access to reliable communications for effective and prompt response. The United States Code of Federal Regulations requires fire and rescue to be at the scene of an airport accident within three minutes of accident report. At night or during foggy conditions, it may be difficult to reach an airport location within the required time. To meet this strict requirement, Fire and Rescue response could be aided by the use of airport surface situational awareness. A surface wireless network data link system could be used to transport surface radar information to all rescue vehicles while en-route to the accident scene.

Other airport tenants such as aircraft fueling and food services could benefit from the use of a wireless voice and data system. Fuel and catering service vehicles could use this network to make schedule adjustments and provide progress reports to their central operations. 


\begin{tabular}{|c|c|c|c|c|c|c|c|c|c|}
\hline \multicolumn{10}{|c|}{ DFW Operations Statistics } \\
\hline \multicolumn{10}{|c|}{ January, 2004} \\
\hline \multicolumn{10}{|l|}{ Jan-04 } \\
\hline & & & & & & & & & \\
\hline & & & & Total CYTD & Total CYTD & & Total FYTD & Total FYTD & \\
\hline & Jan-04 & Jan-03 & & 2004 & 2003 & CYTD & 2004 & 2003 & FYTD \\
\hline $\begin{array}{c}\text { Carrier } \\
\text { Type }\end{array}$ & Operations & Operations & $\%$ Change & Operations & Operations & $\%$ Change & Operations & Operations & $\begin{array}{c}\% \\
\text { Change } \\
\end{array}$ \\
\hline Air Carrier & 44,109 & 40,959 & $7.7 \%$ & 44,109 & 40,959 & $7.7 \%$ & 171,630 & 164,201 & $4.5 \%$ \\
\hline Air Taxi & 22,714 & 22,342 & $1.7 \%$ & 22,714 & 22,342 & $1.7 \%$ & 91,991 & 89,592 & $2.7 \%$ \\
\hline $\begin{array}{c}\text { General } \\
\text { Aviation } \\
\end{array}$ & 491 & 533 & $-7.9 \%$ & 491 & 533 & $-7.9 \%$ & 2,061 & 2,516 & $-18.1 \%$ \\
\hline Military & 5 & 5 & $0.0 \%$ & 5 & 5 & $0.0 \%$ & 36 & 44 & $-18.2 \%$ \\
\hline & 67,319 & 63,839 & $5.5 \%$ & 67,319 & 63,839 & $5.5 \%$ & 265,718 & 256,353 & $3.7 \%$ \\
\hline
\end{tabular}

Table 3. DFW Operations-January 2004

Source: $\underline{\text { http://www.dfwairport.com/stats/04/01/operations-jan04.xls }}$

\section{DALlas Fort WORTH AirPort -}

\section{REQUIREMENTS EVALUATION}

Dallas Fort Worth (DFW), a level 12 airport, is one of the largest and busiest airports in the United States. Depending on the time of year, it shares the top spot for busiest airport in the nation with Chicago and Atlanta airports. The number of operations statistics at DFW can be observed in Table 3. DFW is host to very large airline facilities, as well as, small airline operations, cargo carriers, concessionaire locations, and typical flight support structures such as fuel and catering. The FAA has a TRACON, two operational ATCT's and several facilities supporting navigation, surveillance, weather and visual aids on airport grounds.

The Dallas airport services 24 airlines and consists of four terminals for passenger traffic, with a fifth one being placed into operation in July 2005. The largest airline is American Airlines, which has approximately 500 arrival and departures per day, along with American Eagle Airlines, which has approximately 150 arrival and departures per day. These two comprise approximately $73 \%$ of the entire airport operation for domestic flights and $80 \%$ of the international traffic. There are two large cargo operations at the DFW Airport, UPS and FEDEX and several other domestic and international carriers.

To satisfy airport tenant requirements and enable continuous high performance and elevated productivity, airport tenants require wired and wireless communication systems that are used for fueling, de-icing, flight planning, weather, reservation systems, Tower/Ramp/Gate operations, aircraft maintenance, baggage handling and more. Communication requirements vary depending on the airport tenant operation. The following reflects some of the communication requirement findings which a recent study conducted by NASA under the ACAST program identified [3]. This study revealed numerous requirements for airground and ground-ground communications at DFW.

Wireless communication for all airline activity mainly consists of VHF radios for communications between airline ramp and aircraft pilot. ARINC provides both voice and data communications services in the VHF band to most airlines at DFW. ARINC's data link services operate at rates of 2.4 or $31.5 \mathrm{KBps}$. For other airline surface activities, trunk radio systems operating in the 400 or 800 $\mathrm{MHz}$ ranges are used. At DFW, approximately 70 frequencies are available for airline to pilot communication and around 180 frequencies are used for airline trunk radio systems. It is estimated that a throughput of $168 \mathrm{Mbps}$ is required to meet all data transfer at the airport [3]. Critical airline communications systems require redundancy with a restoral time of 6 seconds and a Bit to Error of $1 \times 10^{-5}$. To meet the expected growth in airport operations, doubling of flights over the next 10 years, it will be required to increase data throughput capabilities and frequency channel availability. Services such as cockpit moving maps for increased situational awareness, controller pilot data link, Automated Dependent Surveillance and other envisioned systems will demand higher throughputs. 
FAA communication systems utilize many diverse media types such as copper, fiber, microwave, and wireless technology and span various FAA buildings around airport grounds. These systems carry ATC voice, surveillance, weather, and other traffic that are critical to DFW airport operations. They also have ample redundancy and diversity built-in, as they were designed with criticality and aviation safety in mind. Analysis of the bandwidth requirement for FAA communications at DFW showed that approximately $30 \mathrm{Mbps}$ is required between the TRACON facility and the two ATCTs, and approximately $12 \mathrm{Mbps}$ is required from the TRACON to other FAA facilities. Spectrum analysis reveals that around 152 frequencies are being used for ATC voice communication, radio navigation and other services. [3]

\begin{tabular}{|c|c|c|c|}
\hline Facility Type & Facility & $\begin{array}{l}\text { No. of } \\
\text { Circuits }\end{array}$ & $\begin{array}{c}\text { Circuit } \\
\text { Type }\end{array}$ \\
\hline \multirow{13}{*}{$\begin{array}{c}\text { Instrument } \\
\text { Landing Systems }\end{array}$} & RWY 36R & 4 & 2 wire \\
\hline & RWY 36L & 8 & 2 wire \\
\hline & RWY 13R & 6 & 2 wire \\
\hline & RWY 18R & 16 & 2 wire \\
\hline & RWY 17R & 5 & 2 wire \\
\hline & RWY 31R & 4 & 2 wire \\
\hline & RWY 35C & 8 & 2 wire \\
\hline & RWY 17C & 13 & 2 wire \\
\hline & RWY 17L & 15 & 2 wire \\
\hline & RWY 35R & 5 & 2 wire \\
\hline & RWY 35L & 7 & 2 wire \\
\hline & RWY 18L & 4 & 2 wire \\
\hline & Admin. & 24 & 2 wire \\
\hline \multirow{4}{*}{ Radar System } & ASR 9 & 10 & 4 wire \\
\hline & $\begin{array}{c}\text { ASR } 9 \\
\text { Monitoring }\end{array}$ & 2 & 4 wire \\
\hline & Mode S & 2 & 4 wire \\
\hline & Admin. & 2 & 2 wire \\
\hline \multirow{3}{*}{$\begin{array}{c}\text { Runway Visual } \\
\text { Range }\end{array}$} & RO RVR & 5 & 4 wire \\
\hline & MID RVR & 3 & 4 wire \\
\hline & TD RVR & 6 & 4 wire \\
\hline \multirow{4}{*}{ Visual Aids } & ALS & 6 & 4 wire \\
\hline & PAPI & 13 & 4 wire \\
\hline & MALSR & 7 & 4 wire \\
\hline & VASI & 1 & 4 wire \\
\hline Communications & RTR's & 45 & 4 wire \\
\hline
\end{tabular}

Table 4 CNS Communication Requirements

To deliver communications, navigation, surveillance and other services, DFW requires approximately 221 dedicated point-point circuits as shown in Table 4. To meet Instrument Landing System requirements for the entire airport, a total of 119 dedicated circuits are needed. These circuits include localizer, glide slope, middle marker, and inner marker systems serving several runways each with a different category rating. For connectivity to VHF/UHF radio equipment, a total of 45 four wire circuits are required. These circuits are used to transport controller, pilot and push to talk information from the ATCT to various RTR facilities around airport grounds. Two surveillance facilities located at the airport require 16 circuits to remote primary and secondary surveillance tracks, weather and monitoring information. Data rates for these services range between $2.4 \mathrm{KBps}$ and 9.6 KBps.

For air-ground communications DFW has numerous channels in use by a variety of airport tenants operating in different frequency bands. As seen on Table 5 the FAA uses 7 VHF channels for surface operations, three for Predeparture clearance and four for ground control. Airlines operating on the airport and some operators directly servicing airlines use a total of 188 land mobile radio channels. Table 6 shows a diverse list of airport tenants providing other types of services to the flying public, along with the frequencies and number of channels in use at DFW. These frequencies are primarily used for handheld radio systems, land mobile radio and fixed radio.

For airport authority operations, it is estimated that that bandwidth requirements are below $10 \mathrm{Mbps}$ within the airport and about $7 \mathrm{Mbps}$ for outside communications. DFW port authority wireless communications consists of a secure land-mobile radio system that operates in the 800 $\mathrm{MHz}$ range with about 32 frequencies as well as a $400 \mathrm{MHz}$ radio system with 6 frequencies. [1]

\begin{tabular}{|c|c|c|}
\hline User & $\begin{array}{c}\text { Frequency Range } \\
\text { Used in } \mathrm{MHz}\end{array}$ & $\begin{array}{c}\text { \# of } \\
\text { Channels }\end{array}$ \\
\hline AMERICA WEST & $464.6-469.6$ & 2 \\
\hline AMERICAN AIRLINES & $451.5625-467.925$ & 74 \\
\hline ATLANTIC SOUTHEAST & $462.125-469.7$ & 8 \\
\hline BRITISH AIRWAYS & $460.675-465.675$ & 2 \\
\hline CONTINENTAL AIRLINES & $465.725-465.8$ & 2 \\
\hline DELTA AIR LINES INC & $460.65-467.725$ & 10 \\
\hline FRONTIER AIRLINES & $461.95-466.95$ & 2 \\
\hline LUFTHANSA AIRLINES & $460.75-465.75$ & 2 \\
\hline MIDWEST EXPRESS & $464.275-464.475$ & 2 \\
\hline NORTHWEST AIRLINES & 464.4375 & 1 \\
\hline SKYWEST AIRLINES & $460.65-465.65$ & 2 \\
\hline TRANS WORLD & 460.675 & 1 \\
\hline UNITED AIR LINES & $460.65-469.975$ & 42 \\
\hline US AIRWAYS, INC. & $460.65-465.8$ & 4 \\
\hline ARINC & $451.2375-457.1375$ & 10 \\
\hline ARINC & $806.5625-860.8875$ & 24 \\
\hline FAA & $118.00-137.00$ & 7 \\
\hline
\end{tabular}

Table 5 DFW Airline Channel Information

An evaluation of all airport requirements shows that an estimate of $168 \mathrm{Mbps}$ of bandwidth is necessary to meet 
existing requirements. It is possible that most requirements could be met by a properly designed wireless communications system. However, there are added requirements that need to be met in order to transport critical safety of life information on the same system as non-critical information. The FAA requires that critical information is transported either via wire or wireless media using separate communications systems. It may be possible that utilize frequency division or code division multiplexing to provide the separation of critical and non-critical information.

\begin{tabular}{|l|r|c|}
\hline \multicolumn{1}{|c|}{ User } & $\begin{array}{c}\text { Frequency Range } \\
\text { Used }\end{array}$ & $\begin{array}{c}\text { \# of Channels I } \\
\text { Frequencies }\end{array}$ \\
\hline Dollar Rent A Car & 463.8625 & 1 \\
\hline Alamo Rent A Car & $463.8625-464.1625$ & 2 \\
\hline AVIS Rent A Car & $457.6-467.8$ & 3 \\
\hline Hertz Rent A Car & $461.1625-469.3375$ & 18 \\
\hline DALLAS MARRIOTT DFW & $462.825-469.7125$ & 6 \\
\hline HYATT REGENCY & $461.525-468.875$ & 4 \\
\hline HOLIDAY INN EXPRESS & 160.1025 & 1 \\
\hline HOLIDAY INN SELECT & $461.85-466.85$ & 2 \\
\hline WYNDHAM DALLAS & $467.7625-467.8125$ & 2 \\
\hline FEDERAL EXPRESS CO. & $460.75-466.1125$ & 4 \\
\hline UNITED PARCEL SERVICE & $451.3125-469.8625$ & 56 \\
\hline LSG SKYCHEFS & $451.7-468.45$ & 12 \\
\hline OGDEN AVIATION FUELING & $464.475-464.975$ & 2 \\
\hline
\end{tabular}

Table 6 DFW Tenant Channel Usage Information

The performance requirements assessment for DFW revealed that minimum data rates required are as follows:

- FAA: $\sim 30$ Mbps (TRACON to Tower), $\sim 12$ Mbps (TRACON or ATCT to RTRs, NAVAIDS, ASR-9 Radar, DBRITE, Weather Sensors, etc.). Does not include ASDE-3.

- Airlines: $\sim 65 \mathrm{Mbps}$

- Airport: 7 Mbps for data

- Passenger comm.: 54 Mbps data only.

These are existing requirements and do not consider any future information transport needs.

\section{CONCLUSION}

Most airports in the United States use fiber optics, copper cable, microwave systems, wireless local area networks or leased telco services to transport critical information. FAA relies on copper cable and fiber optic systems to transport most of in airport ground-ground communications and VHF/UHF for air-ground communications. Airline airground communications rely on leased services and, depending on the size of operation, airline owned/leased wireless and wired communication systems are used for internal airline communications. Airport Authority relies on copper, fiber optics and VHF systems to manage airport operations.

Limitations posed by existing systems need to be overcome to satisfy future requirements. The depletion of aeronautical VHF channels needs to be addressed in order to satisfy existing requirements and meet future ones. Although data link capabilities are available to the aircraft, they have limited capacity and it is in question whether they will be able to meet future applications data throughput requirements.

NAS modernization will require changes in communications infrastructure. Although some systems in use today provide interfaces suitable for copper media, the increased system migration into the digital domain will make copper cable a difficult media to utilize. Fiber optic networks offer the bandwidth and reliability required to modernize inside airport communications. However, they come with an elevated deployment price tag with the potential for disruption to airport operations during implementation. Wireless systems are not immune to problems. A wireless system can be vulnerable to intentional or unintentional radio frequency interference (RFI). Consequently, measures must be taken to reduce or eliminate the possibility of RFI.

It is envisioned that to support the growing demands for information transfer, a hybrid communications system will be required. An ideal airport surface communications system would use existing communications assets and wireless technologies to increase reliability and availability. The wired system would mitigate frequency interference while the wireless system would provide backup during cable cuts.

Airports in the United States have a variety of tenants, each with a unique set of communication requirements. Their numerous activities must flawlessly operate to deliver the expected performance of a modern airport operation. These activities, in most cases, are dependent on reliable communications systems with the potential to adapt and evolve with the operation. Most tenants require high quality service performance for both voice and data services along with high security and reliability. 


\section{REFERENCES}

[1] White Paper: Spectrum Depletion Analysis, MITRE Corporation, Melvin Zelster, Frederick Morser, Philip Long, Frank Box, April 2003.

[2] FAA NAS System Requirements Specification NAS-SR1000

[3] Surface CNS Network Requirements, Task Order 2, Science Applications International Corporation.

\section{BIOGRAPHY}

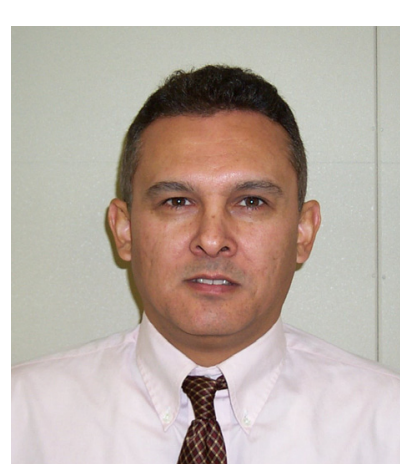

Rafael D. Apaza has been working with the Federal Aviation Administration Airway Facilities involved in Communications and Surveillance systems (1987 - 2004). He holds a BSEE (1985), a MSEE (1995) from Wayne State University, and a MCIS (2001) from the University

of Michigan. He is currently working for the FAA Aviation Research Office, ATO-P R\&D, supporting NASA Glenn Research Center. 